\title{
Predicting Soil Corrosivity along a Pipeline Route in the Niger Delta Basin Using Geoelectrical Method: Implications for Corrosion Control
}

\author{
Kenneth S. Okiongbo ${ }^{*}$, Godwin Ogobiri \\ Department of Geology \& Physics, Niger Delta University, Bayelsa State, Nigeria \\ Email:*okenlani@yahoo.com
}

Received November 29, 2012; revised February 18, 2013; accepted February 25, 2013

\begin{abstract}
The corrosivity of the top three metres of the soil along a pipeline route was determined using soil electrical resistivity for the emplacement of a conduit intended to serve as a gas pipeline. Fifty-six Schlumberger vertical electrical soundings (VES) were carried using a maximum current electrode separation ranging between $24-100 \mathrm{~m}$ at $2.0 \mathrm{~km}$ interval. The data were interpreted using a 1D inversion technique software (1X1D, Interpex, USA). Model resistivity values were classified in terms of the degree of corrosivity. Generally, the sub-soil condition along the pipeline route is non-aggressive but being slightly or moderately aggressive in certain areas due to local conditions prevailing at the measuring stations. Based on the corrosivity along the pipeline route, appropriate cathodic protection methods are prescribed.
\end{abstract}

Keywords: Soil Corrosivity; Geoelectrical; Pipeline; Groundbed; Niger Delta

\section{Introduction}

The Niger Delta Basin is one of the prolific crude oil provinces in the world and as such there is an extensive network of pipelines. Pipelines play an extremely important role through-out the world as a means of transporting gases and liquids over long distances from their sources of production to distribution terminals. A buried operating pipeline is unobtrusive and is rarely known except at valves, pumping, compressor stations or terminals, hence it is a preferred means of transportation of gases and liquids. A vast majority of underground pipelines is made of carbon steel, and these steels have inadequate alloy additions to be considered corrosion resistant and undergo a variety of corrosion failure modes/mechanisms in underground environments, including general corrosion, pitting corrosion, and stress-corrosion cracking (SCC) [1]. Given the implications of pipeline failures, and the role that external corrosion plays in these failures, it is apparent that prediction of corrosion and thus proper corrosion control can have a major impact on the safety, environmental preservation and the economics of pipeline operation.

In this instance, a circular conduit of approximately $110 \mathrm{~km}$ in length was planned to be built from Obirikom (Rivers State) to Oben (Edo State) in the Niger Delta

\footnotetext{
"Corresponding author.
}

Basin, Nigeria. The conduit would serve as a gas pipeline. The engineers involved in the project considered that the conduit would be trenched. Soil corrosion in this case was anticipated in regards to the pipeline which is expected to be buried within the top three metres of the soil. Ruptured pipelines due to corrosion failure are ubiquitous in the Niger Delta, resulting in crude oil spills with devastating ecological consequences. The control and effective minimization of corrosion are possible by the proper understanding of the material characteristics and performance as well as the conditions of the environment in which the material will reside. This enhances the design life of steel components and structures in contact with the soil. Aside, it saves money, improves safety and protects the environment. A key requirement to prevent corrosion and thus ensure a satisfactory performance of a piping system is the design and installation of an effective cathodic protection system. The cathodic protection (CP) system is a proven, highly effective and elegant method of corrosion control. CP can be either galvanic or impressed current cathodic protection system, depending on whether the soil resistivity is low or high. Soil corrosivity is not a measureable parameter. Therefore, in the evaluation of soil corrossivity/aggressivity, a host of critical parameters characteristic of the soil are usually employed. These include soil kind, condition, water content, $\mathrm{pH}$ value, redox potentials, microbiological activity, 
anion and cation levels and electrical resistivity. The electrical resistivity is highly significant in cases of insitu determination of the degree of corrosiveness of soils. It is a main indicator of the corrosiveness of soils, as the rate of corrosion is a function of the electrical conductivity. Consequently, in determining an appropriate groundbed location for optimum cathodic protection system, the design of the cathodic protection is essentially based on shallow in-situ soil resistivity [2].

This paper describes the application of the shallow vertical electrical resistivity (VES) method to determine the electric resistivity variations with lithology and depth with a view to determining the corrosivity of the top three metres of the soil for the emplacement of a conduit intended to serve as a gas pipeline. The implications of the soil corrosivity variation to corrosion control are examined.

\subsection{Study Area Description}

The project area is located in southern Nigeria between latitudes $4^{\circ} \mathrm{N}$ and $6^{\circ} \mathrm{N}$, and longitude $3^{\circ} \mathrm{E}$ and $6^{\circ} \mathrm{E}$ (Figure 1). Physiographically the project area lies within the low Deltaic plain and freshwater swamps. The area is underlain by the deposits of the modern and Holocene delta top deposits. They result from the sediment laden discharges of the River Niger that is spread on the delta by its various tributaries. The sediment is generally an admixture of medium to coarse-grained sands, sandy clays, silts and clays that eventually settle in fluvial/tidal chan- nel, tidal flat and mangrove swamp environments [3].

\subsection{Background: Resistivity Survey}

The electrical resistivity of the soil is a parameter that depends mainly on the salt concentration in the pore fluid, the particle size, and the tortuosity of the conduction path, the latter being related to porosity and structure [4]. In coarse soils, the salt concentration and porosity are fundamental parameters, while in clayey soils, particle surface is also relevant. In general, gravels have higher resistivity than sands, and sands have higher resistivity than clays. In the presence of salty waters, as is the case in marine environments, the opposite trend may be observed [4].

This is because conductivity in soils is governed by conductivity of pore fluid and tortuosity. The higher the tortuosity, the lower the electrical conduction. Although tortuosity of clays is higher than that of granular soils, the higher conductivity of clays is due to the presence of adsorbed cations on particle surfaces.

When there is high salt concentration in the pore fluid, the electrical conduction through the pore fluid becomes dominant and the phenomenon is mainly controlled by tortuosity [5]. Therefore, at very high salt concentration in the pore fluid, the electrical conductivity of granular materials may become higher than that of clays due to the lower tortuosity of their conduction path. Table 1 displays the resistivity range commonly encountered in some geological materials. One may note that the wide

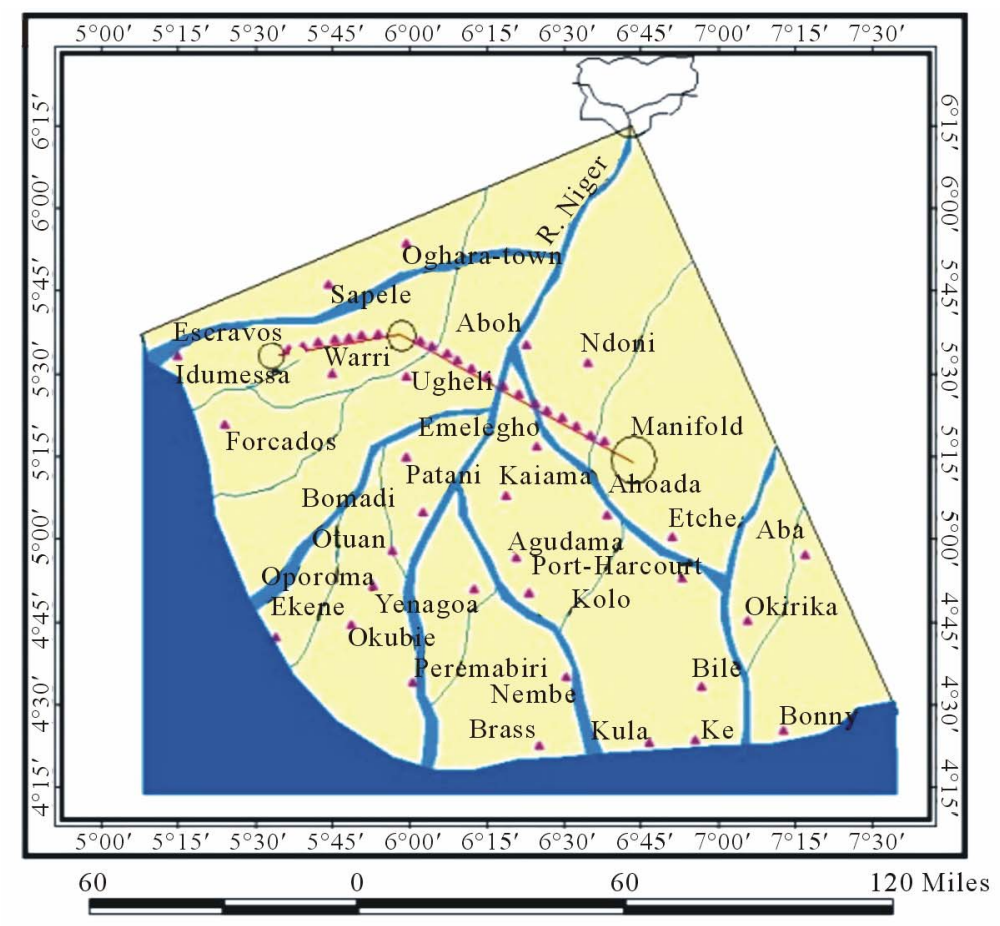

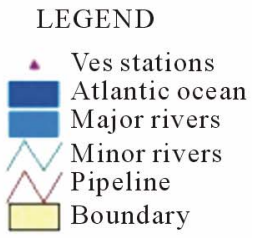

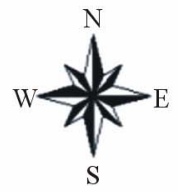

Figure 1. Map of study area showing pipeline route. 
Table 1. Representative values of resistivity for some geologic materials [7].

\begin{tabular}{cc}
\hline Material type & Resistivity $(\Omega \mathrm{m})$ \\
\hline Clay & $1-100$ \\
Silts & $10-150$ \\
Alluvium & $10-800$ \\
Sandstone & $8-4000$ \\
Shale & $20-2000$ \\
Granite & $5000-5.0 \times 10^{6}$ \\
Basalt & $1000-10^{6}$ \\
Groundwater (fresh) & $10-100$ \\
Sea water & 0.2 \\
\hline
\end{tabular}

range of resistivity values corresponds to different environmental conditions of the materials, particularly saturation and salt concentration in the pore fluid. Thus for a given material, the higher the saturation and salt concentration in the pore fluid, the lower the resistivity values.

\section{Materials and Method}

The location of the pipeline route is shown in Figure 1. The position for the VES stations was marked out by surveyors of the geotechnical consultants commissioned to carry out the geophysical investigation along the pipeline route. The resistivity sounding was at $2.0 \mathrm{~km}$ intervals for total of $110 \mathrm{~km}$. Although $2 \mathrm{~km}$ station interval was initially adopted, due to poor accessibility in some sections of the profile, this was adjusted to $1-3 \mathrm{~km}$ intervals in a few areas. A total of 56 soundings were occupied along the pipeline route using the Schlumberger configuration. Basically, the potential electrodes $(M \& N)$ remain fixed and the current electrode $(\mathrm{A} \& \mathrm{~B})$ is expanded symmetrically about the centre of the spread. The Schlumberger data are mostly taken in overlapping segments because at each step of $A B$ spacing, the signals of the resistivity meter become weaker. Therefore, MN spacing was enlarged and two values for the same $A B / 2$ were measured, one for the short and one for the long MN spacing. Maximum current electrodes separation used in this survey ranges between $24-100 \mathrm{~m}$. Field precautions observed to ensure good VES data quality included firm grounding of the electrodes, and checking for current leakage and creeps to avoid spurious measurements. Also, adequate offsets were made for electrode positions that coincided with water logged areas. The instrument used was an Abem Terrameter SAS 3000, a digital self averaging instrument for DC resistivity work. A portable $12 \mathrm{~V}$ battery was used as the power source while four stainless metal stakes were used as electrodes.
The positions and surface elevations of VES sites were also recorded during survey with a GPS receiver. Soil borings at every VES station were performed to $5 \mathrm{~m}$ depths using a locally fabricated, easily dismantleable percussion rig. During the boring operations, disturbed samples were regularly collected at about $1.0 \mathrm{~m}$ intervals and also when a change of soil type was noticed. The field measurement of current, $I$ and potential difference, $\Delta V$ were used in the computation of the apparent resistiveity $\rho_{a}$ given by

$$
\rho_{a}=K \frac{\Delta V}{I}
$$

where $K$ is the geometrical factor given by

$$
K=\frac{\pi a^{2}}{b}\left[1-\frac{b^{2}}{4 a^{2}}\right]
$$

where

$a=$ half the distance between current electrodes;

$b=$ distance between potential electrodes.

The data obtained was subjected to computer assisted iterative interpretation using 1-D inversion technique software (1X1D, Interpex, USA). The software yields the number, thickness, resistivity of the various layers and the root mean square (rms) error. The prediction of the degree of in-situ corrosiveness from resisivity measurements of the soil was made using the classification shown in Table 2 [6]. The classification was made at depths of 1.0, 1.5, 2.0, 2.5 and $3.0 \mathrm{~m}$ for each VES site. The results are presented in Table 3.

\section{Results and Discussion}

The geoelectrical curves obtained are shown in Figure 2 and vary considerably throughout the study area. Typical forms of these curves are HA, HK, KH and A types. Most of the sounding curves obtained were of the HAtype $\left(\rho_{1}>\rho_{2}<\rho_{3}<\rho_{4}\right)$, i.e. a bowl shaped curve with a steeply descending left branch and a gently ascending right branch representing the presence of four geoelectric layers. The descending left branch indicates a resistive top soil underlain by a conductive material (wet clays). The results of the interpretative models at the various stations are shown in Table 3. The results reveal widely

Table 2. Classification of soil aggressivity [6].

\begin{tabular}{cc}
\hline RESISTIVITY (Ohm-m) & SOIL AGGRESSIVITY \\
\hline Up to 10 & Very Strongly Aggressive (VSA) \\
$10-60$ & Moderately Aggressive (MA) \\
$60-180$ & Slightly Aggressive (SA) \\
180 - above & Practically Non-Aggressive (PNA) \\
\hline
\end{tabular}


Table 3. Electrical resistivity at each VES station.

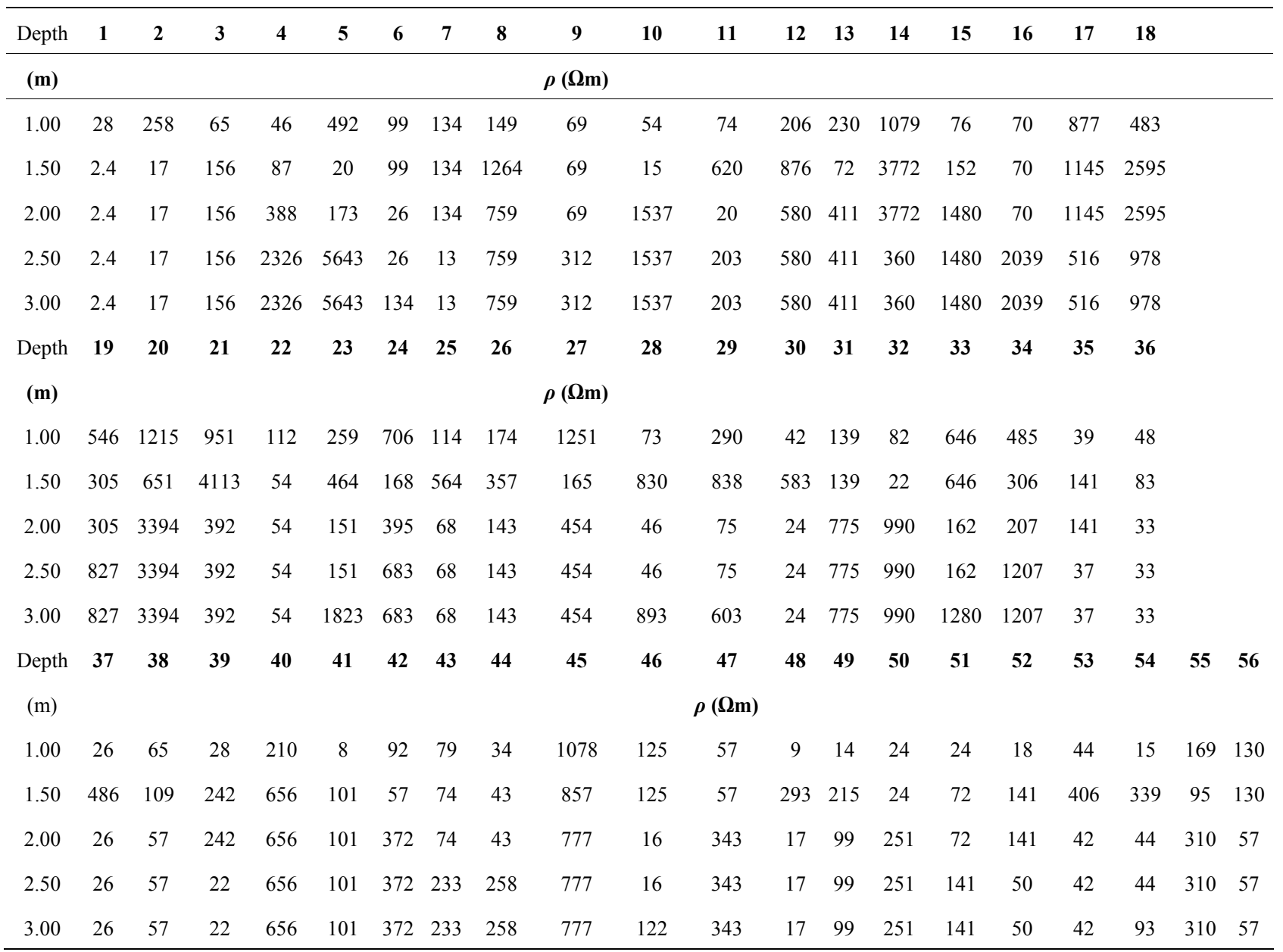
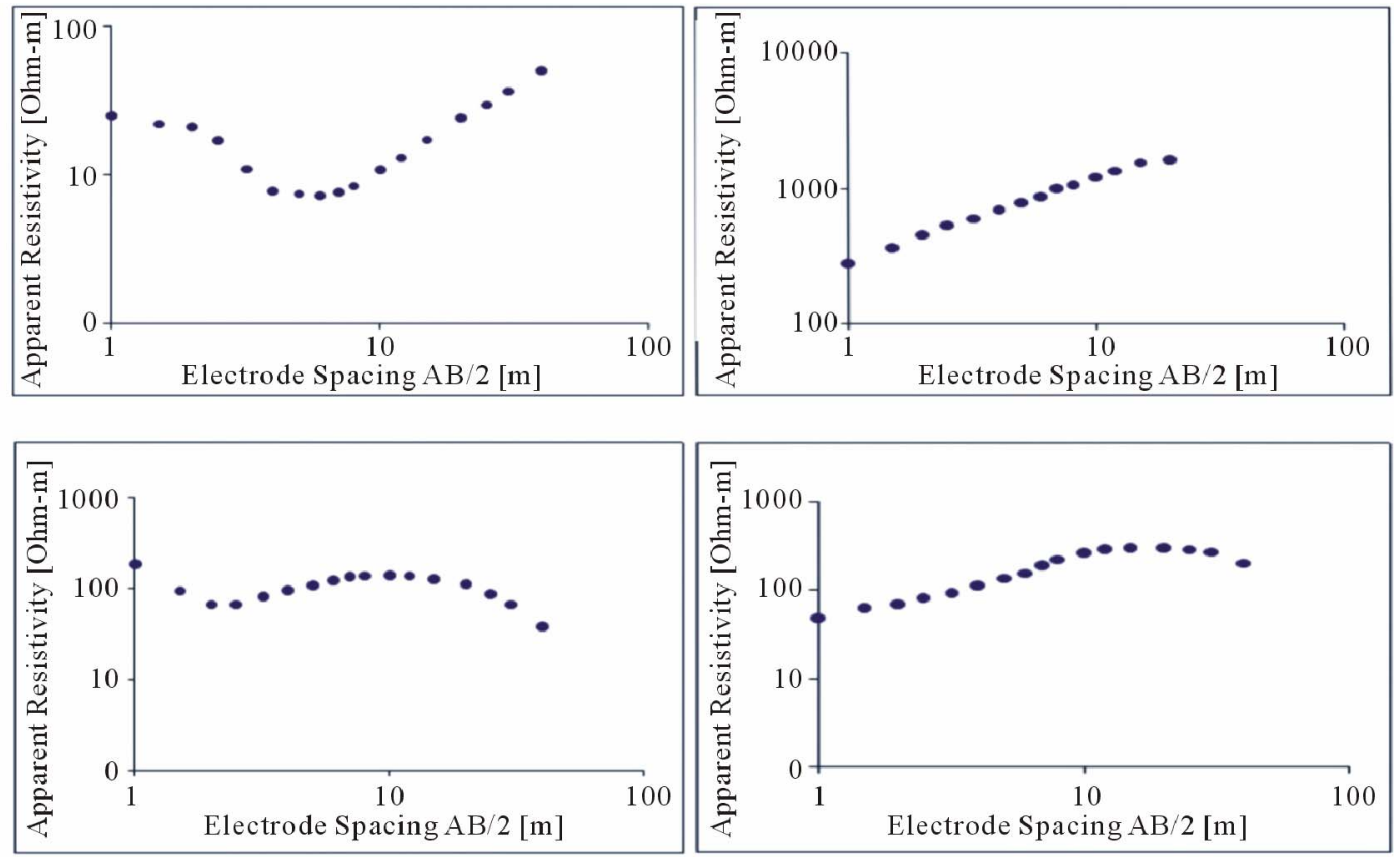

Figure 2. Examples of the obtained electric sounding curves. 
irregular variation in resistivity both vertically and laterally (Figures 3-5). This is an indication of the very complex depositional environment of the area. Since the conduit is expected to be buried within the top three metres of the soil, we restrict our interpretation to the top three metres only. The first unit corresponding to a depth range of $0-1.0 \mathrm{~m}$ (Table 3), representing the surface soil exhibits a resistivity range of $28-1251 \Omega \mathrm{m}$. The variations of the surface-soil resistivity are attributed to local conditions prevailing at the measuring stations. The relatively higher values of resistivity indicate dry soils and the presence of coarse sand, and the relatively lower values indicate wet grains of finer sizes and different mineralogical composition, such as fine sands, silts and clays. The finer the size of the grains, the greater the specific surface area per unit of bulk volume, grain volume, or pore volume, which enables the grains to absorb charged ions at their surfaces and thus the conduction of electric current will be easier [5]. The depth range of $1.0-1.5 \mathrm{~m}$ and $1.5-2.0 \mathrm{~m}$ (Table 3), representing the aeration zone above the water table, exhibits resistivity range of 2.4 $3772 \Omega \mathrm{m}$, while the depth ranges of $2.0-2.5 \mathrm{~m}$ and $2.5-$ $3.0 \mathrm{~m}$ the water-table depth, exhibits a resistivity range of 2.4 - $2326 \Omega \mathrm{m}$. Generally, we attribute resistivity variations to changes in the lithology, size, and shape of the grains, pore-water salinity and clay content [8].

The variations of the soil resistivities at the $1.0 \mathrm{~m}$ depth for all VES stations are shown in Table 3 and Figure 3. The dataset shows that about $46 \%$ of the sampled points are non-aggressive $(\rho>180 \Omega \mathrm{m}), 25 \%$ of the sampled points are slightly aggressive $(\rho=61-180 \Omega \mathrm{m})$ while $29 \%$ of the sample points are moderately aggressive $(\rho=11-60 \Omega \mathrm{m})$. Generally the shallow subsoil condition at the $1.0 \mathrm{~m}$ depth is non-aggressive (effective aggressivity) (Figure 3), and corrosion risk to metallic structures at this depth is expected to be low, the few areas that are slightly or moderately aggressive are localized. The moderately aggressive or very strongly aggressive areas are anodic regions characterized by low resistivities such as in the vicinities of stations 1, 41, 48, 49, 50, 51, 52 and 54. These regions can form corrosion cells. The formation of large corrosion cells which can lead to severe corrosion failures are associated with low resistivities. Low resistivities are indicative of good electrical conducting paths usually due to reduced aeration and excessive electrolytes or wetness in the soil, or mineralization. This posses a significant risk to steel corrosion. Metallic pipes at these areas will have a high probability of degradation.

At the $2.0 \mathrm{~m}$ depth, the dataset shows that $45 \%$ of the

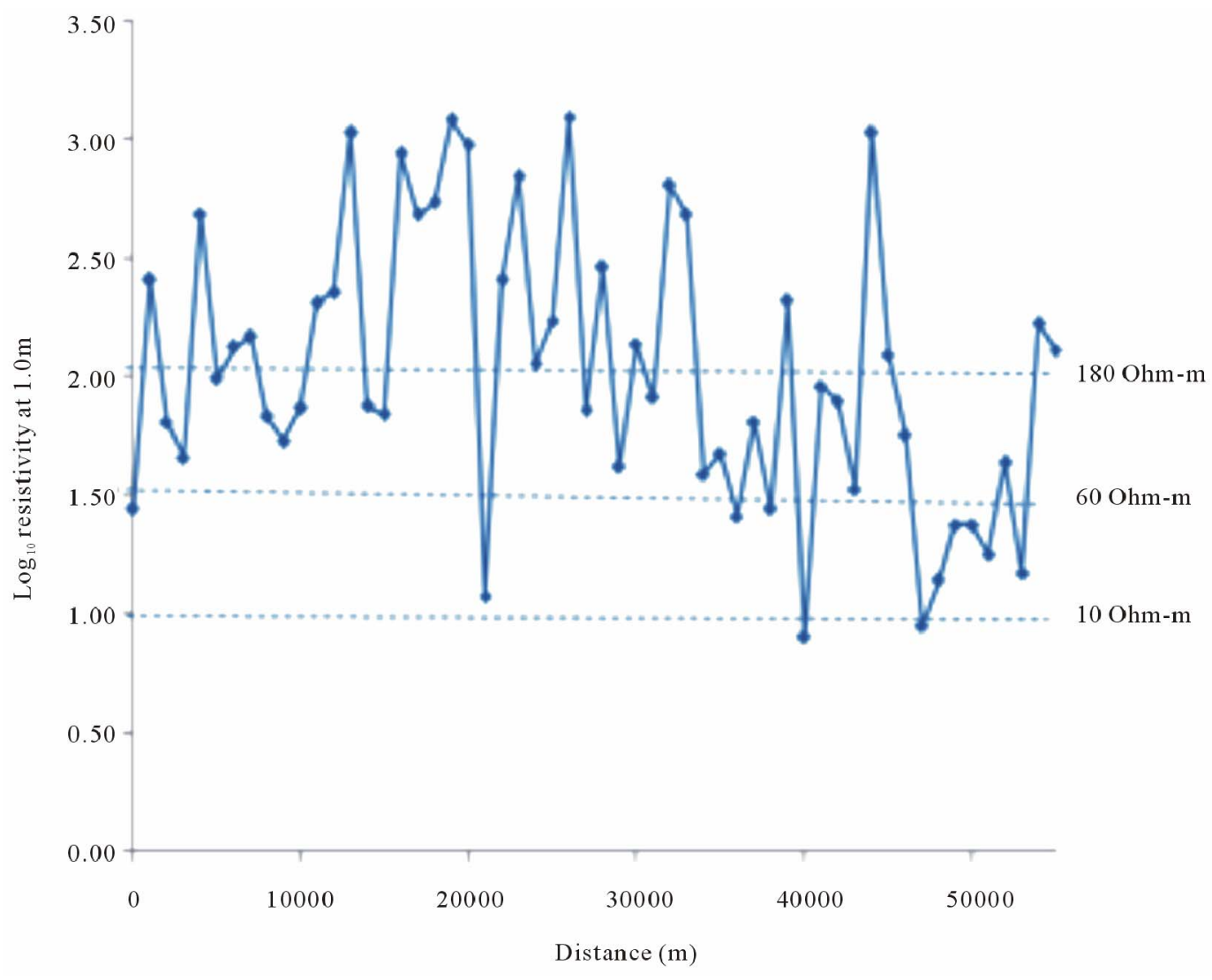

Figure 3. Variation in resistivity along the pipeline route at a depth of $1.0 \mathrm{~m}$. 


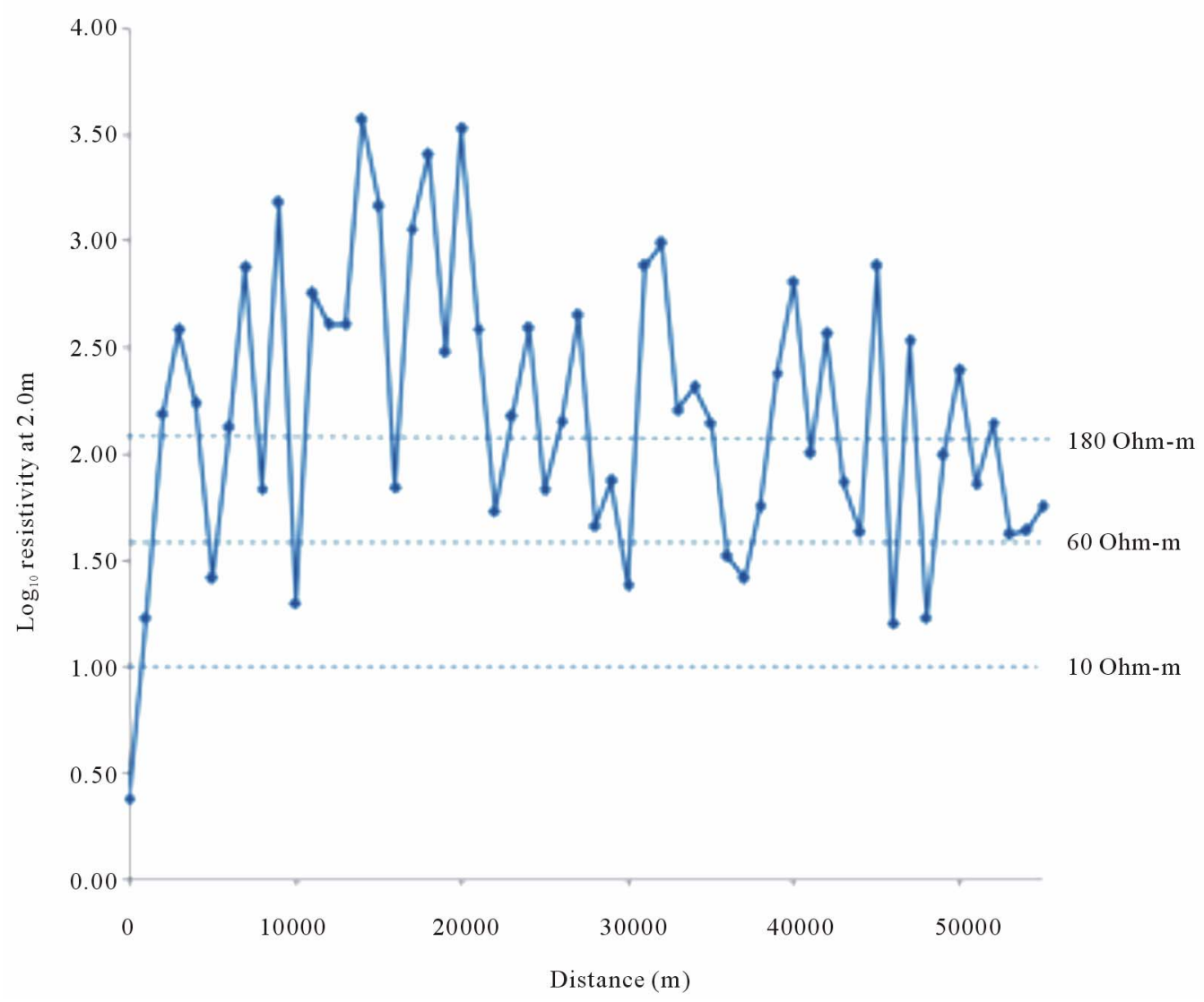

Figure 4. Variation in resistivity along the pipeline route at a depth of $2.0 \mathrm{~m}$.

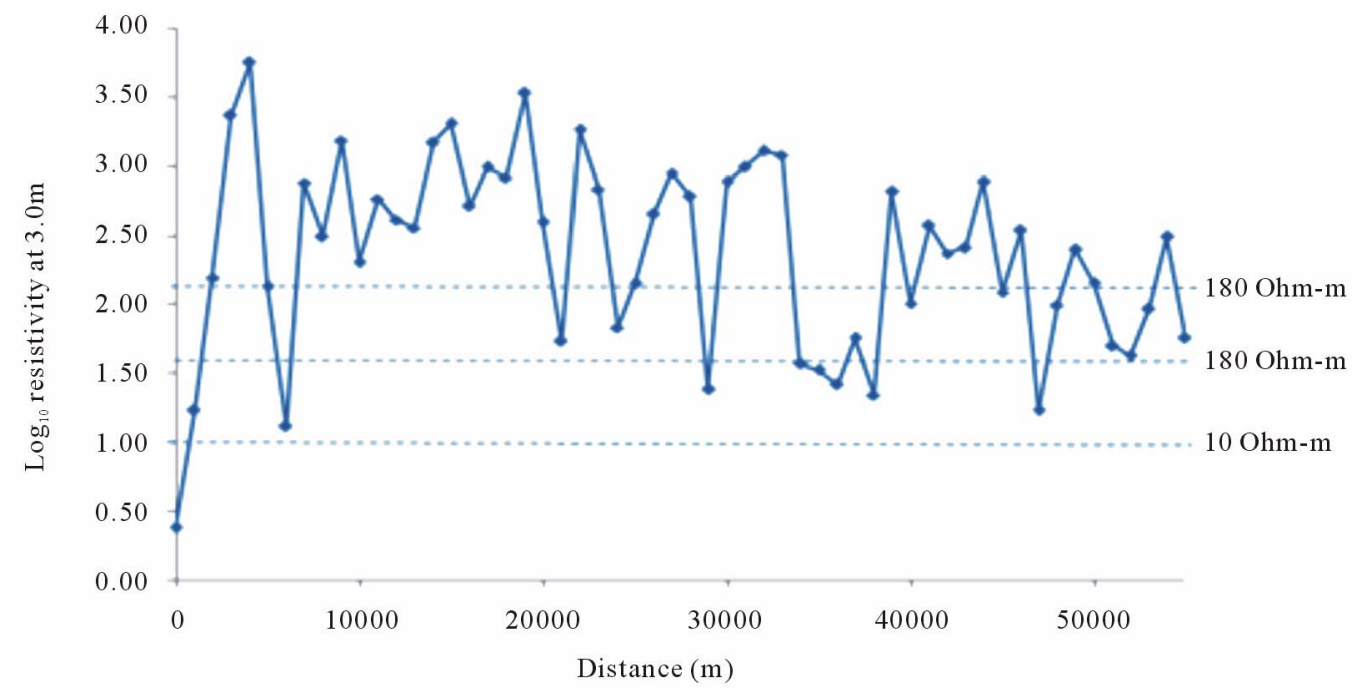

Figure 5. Variation in resistivity along the pipeline route at a depth of $3.0 \mathrm{~m}$.

samples points are non-aggressive, $27 \%$ are slightly aggressive, about $27 \%$ are moderately aggressive and about $2 \%$ are very strongly aggressive.

Generally, the sub-soil at the $2.0 \mathrm{~m}$ depth is non-aggressive (effective aggressivity) (Figure 4). However, there are anodic regions in the vicinities of stations 1,2 ,
$6,7,30,37,44,48$ and 56 . These areas are likely to form corrosion cells and corrosion hazard is likely to be serious at these locations. At the $3.0 \mathrm{~m}$ depth, $57 \%$ of the sampled points are non-aggressive, $11 \%$ of the sampled points are slightly aggressive, while $23 \%$ are moderately aggressive. Generally, the sub-soil at the $3.0 \mathrm{~m}$ depth is 
non-aggressive (effective aggressivity) (Figure 5). Anodic regions characterized by low resistivities oocur at the vicinities of stations $1,2,7,30,35,36,37,38,39,48$, 52 , and 53. These locations are likely to form corrosion cells and corrosion risk is very significant.

\section{Implications for Corrosion Control}

Coating is often applied to prevent corrosion. But all coatings contain some defects or flaws that expose the bare pipeline steel to underground environment and thus undergo corrosion at these coating flaws. Therefore the most effective method to prevent corrosion is to use coating in conjunction with cathodic protection [1]. An important consideration from a design stand point in cathodic protection installation is the location and nature of the site where the anode is placed (groundbed). This is because in selecting groundbed sites, the number of anodes required, the length and diameter of the backfill column, the voltage rating of the rectifier and the power cost are influenced by soil resistivity [2]. For the anodes of the groundbed system to discharge a useful amount of current, the contact resistance between the anodes and the earth must be low. The groundbed resistance $R_{A}$ was derived by [9] and expressed as

$$
R_{A}=\frac{\rho}{2 \pi L}\left[\ln \frac{4 L}{r}-1\right]
$$

where

$$
\begin{aligned}
& \rho=\text { Soil resistivity }(\Omega \mathrm{m}) ; \\
& L=\text { Active bed length }(\mathrm{m}) ; \\
& r=\text { Active bed radius }(\mathrm{m}) .
\end{aligned}
$$

Equation (3) above indicates that to achieve a reduction in the groundbed resistance, given a high soil resistivity in a region, the active bed length and the active bed radius have to be given relatively higher values. Thus, this relationship indicates that higher soil resistivity would require more active bed length to size up the required low bed resistance required for optimum Cathodic Protection (CP) System [10].

Cathodic protection can either be in the form of a rectifier or impressed current type system or sacrificial anode cathodic protection system. Soil corrosivity based on the resistivity data vary along the pipeline route. The sub-soil condition along the pipeline route is generally non-aggressive but being slightly aggressive or strongly aggressive in certain areas. It is therefore necessary that each CP system be designed based on the degree of corrosivity at a given location. For areas that are non-aggressive, with relatively high soil resistivity (Table 3), a high groundbed resistance (Equation (3)) would be expected. An effective groundbed system in these areas would therefore require the reduction in the resistance to earth. This can be achieved by considering a deep-well groundbed system [2]. This is essential in providing good current distribution for an effective CP system in those locations. Aside, in those areas, the natural potential to drive a sacrificial anode groundbed would be low. The sacrificial anode, which is the galvanic anode unit of a cathodic protection system, provides the driving potential from a natural electromotive force between the anode (groundbed) and the steel pipe to be protected. A sacrificial anode groundbed may not therefore be required in those locations, as there will not be enough potential drive for the system. To further reduce the contact resistance, a multiple number of electrodes (anodes in parallel) would be necessary.

The net resistance $R_{\text {net }}$ can then be calculated using the relationship [2].

$$
R_{\text {net }}=\left\{R_{\text {one }} / n\right\} \times\left\{2-\mathrm{e}^{-0.17(n-1)}\right\}
$$

where

$R_{\text {one }}=$ Resistance of one anode;

$n=$ Number of anodes.

It is preferred for the anode to be surrounded by a carbonaceous backfill. The backfill material acts as a sacrificial buffer between the anode and the reaction environment. The backfill particles help to reduce anode resistance to earth, extend anode life by allowing anodic reactions to occur on their surface and provide a porous structure so that the gases produced can escape. Gas entrapment tends to increase the groundbed resistance [2]. A shallow groundbed would be cost effective for areas with low resistivities. If soil conditions are unfavourable, shallow horizontal groundbeds are preferred. It is pertinent to mention that in most parts of the Niger delta, soil resistivity increases with depth, and as a result, the lengths of the active zone of the groundbed should increase to minimize the final operating resistance of the system.

\section{Conclusion}

The geoelectric sounding method has been used to delineate soil profile and resistivity variation along a pipeline route. The variations of electrical resistivities at different depths along the pipeline route are useful for predicting the degree of corrosiveness or aggressivity of the sub-soil. The low resistivity values along the pipeline are areas of significant corrosion cells. Generally, the sub-soil condition along the pipeline route is nonaggressive but it is slightly or strongly aggressive in certain areas. Corrosion cells which may lead to significant corrosion failures may occur in the vicinities of strongly aggressive stations. This investigation has been carried out between July and August during the wet season when corrosion is expected to be maximum due to high moisture content in the top soil. Thus, the results 
and implications are typical of the "worst conditions", in terms of electrochemical corrosion of metallic materials buried in a soil. Each CP system be designed based on corrosivity at a given location. For locations with relatively high soil resistivity, an impressed current $\mathrm{CP}$ with a deep-well groundbed system will be necessary. But for locations with low soil resistivity, a sacrificial anode CP system can be used. If the soil conditions are unfavourable, shallow horizontal groundbeds would be preferred.

\section{Acknowledgements}

The authors are grateful to Prof. E.G. Akpokoje of the Department of Geology, University of Port Harcourt for his support. The cooperation of the Elders and Chiefs of the various communities deserve special appreciation.

\section{REFERENCES}

[1] J. A. Beavers and N. G. Thompson, "External Corrosion of Oil and Natural Gas Pipelines," American Society of Mechanical Engineers Handbook 13C, Corrosion: Environments and Industries No. 05145, 2006, pp. 1015-1024.

[2] A. W. Peabody, "Control of Pipeline Corrosion," NACE, Houston, 1967.

[3] B. Durotoye, "Quarternary Sediments in Nigeria", In: C. A. Kogbe, Ed., Geology of Nigeria, Rockview, Jos, 1975, pp. 431-444.
[4] G. V. Kelly, "Electrical Properties of Rocks and Minerals," In: R. C. Carmichael, Ed., Handbook of Physical Properties of Rocks 1, CRC Press, Boca Raton, 1982, pp. 217-293.

[5] H. S. Salem and G. V. Chilingarian, "Determination of Specific Surface Area and Mean Grain Size from Well Log-Data and Their Influence on the Physical Behavior of Offshore Reservoir," Journal of Petroleum Science and Engineering, Vol. 22, No. 4, 1999, pp. 241-252. doi:10.1016/S0920-4105(98)00084-9

[6] W. V. Baeckmann and W. Schwenk, "Handbook of Cathodic Protection,” Portcullis Press, London, 1975.

[7] US Army Corps of Engineers, "Geo Physical Exploration for Engineering and Environmental Investigations," EM 1110-1-1802, 1995.

[8] H. S. Salem, "Modelling of Lithology and Hydraulic Conductivity of Shallow Sediments from Resistivity Measurements Using Schlumberger Vertical Electric Soundings," Energy Source, Vol. 23, No. 7, 2001, pp. 599-618. doi:10.1080/00908310119202

[9] H. B. Dwight, "Calculation of Resistance to Ground," American Institute of Electrical Engineers, Vol. 55, No. 12, 1936, pp. 1319-1328. doi:10.1109/T-AIEE.1936.5057209

[10] E. D. Sunde, "Earth Conduction Effect in Transmission System," Dover Publications, New York, 1968. 